
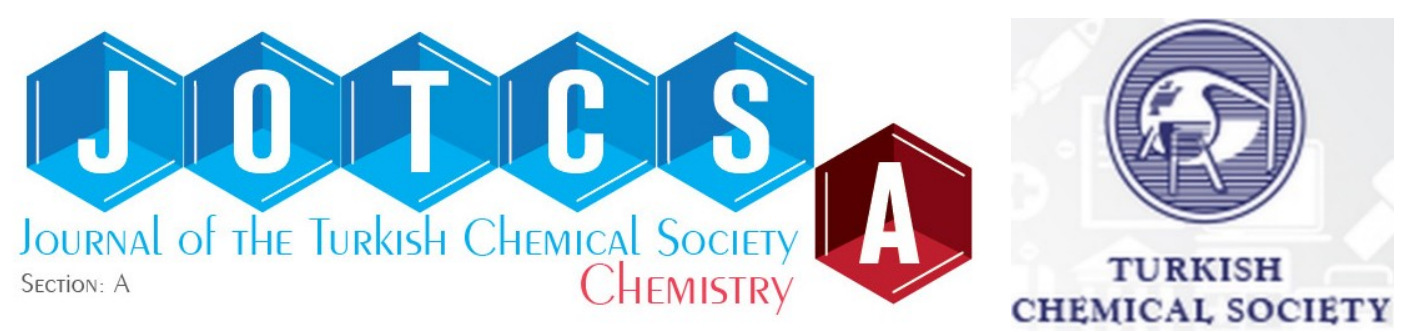

\title{
Enhancement of Mechanical Property of Modified Polyurethane with bis- butyl succinate
}

\author{
Thi Sinh Vo ${ }^{1 *} \square\left(D\right.$, Tran Thi Bich Chau Vo ${ }^{2} D$, Tran Trung Tien ${ }^{1} \square$, \\ and Nguyen Truong Sinh ${ }^{1}$
}

${ }^{1}$ School of Mechanical Engineering, Sungkyunkwan University, Suwon 16419, Korea.

${ }^{2}$ Department of Industrial Management, Can Tho University, Can Tho, Vietnam.

\begin{abstract}
A new crosslinker (bis-butyl succinate, BBS) with terminal alkyne group has been explored in this study that can react with glycidyl azide polymer-based polyurethane (original PU) via "azide-alkyne" click reaction, which has supported enhanced mechanical properties and cross-link densities of modified PUs with BBS. Besides, this crosslinker has been designed and synthesized successfully via an esterification to incorporate with the original PU through the formation of 1,2,3-triazole groups. Notably, the mechanical properties of resultant modified PUs are investigated to indicate a relationship of mole ratio of $[\mathrm{C} \equiv \mathrm{C}] /\left[\mathrm{N}_{3}\right]$ and cross-link density. Specifically, the stress and Young's modulus of the modified PUs increase $(\delta=0.361-1.681$ $\mathrm{MPa}$, and $\mathrm{E}=0.254-5.453 \mathrm{MPa})$, whereas their strain decrease $(\varepsilon=320.8-36.6 \%)$ on increasing the synthesized BBS content (mole ratio of $[\mathrm{C} \equiv \mathrm{C}] /\left[\mathrm{N}_{3}\right]=0-0.10$ ) regarding to the increased rigid 1,2,3-triazole networks, as well as the cross-link densities of the modified PUs increase $\left(\mathrm{V}_{\mathrm{e}}=0.175-5.221 \mathrm{~mol} \cdot \mathrm{cm}^{-3} \cdot 10^{4}\right.$, or $\mathrm{V}_{\mathrm{e}}$ $=0.131-3.842 \mathrm{~mol} \cdot \mathrm{g}^{-1} \cdot 10^{4}$ ) with the BBS content (mole ratio of $[C \equiv C] /\left[\mathrm{N}_{3}\right]=0-0.10$ ) through the MooneyRivlin equation. Resulting that there is an enhancement in the mechanical behaviors of the original PU crosslinked with BBS; concomitantly, the different mole ratio of $[\mathrm{C} \equiv \mathrm{C}] /\left[\mathrm{N}_{3}\right]$ prepared in the present study can reveal new approaches for the design and future application of the original PU with alkyne compounds, as well as their desired cross-link densities can be controlled easily for powerful and selective reactions.
\end{abstract}

Keywords: Polyurethane, Crosslinker, Glycidyl azide polyol, Azide-alkyne click.

Submitted: February 11, 2021. Accepted: March 24, 2021.

Cite this: Vo TS, Vo TTBC, Tran TT, Nguyen TS. Enhancement of mechanical property of modified polyurethane with bis-butyl succinate. JOTCSA. 2021;8(2):519-26.

DOI: https://doi.org/10.18596/jotcsa.878515.

*Corresponding author. E-mail: vtsinh92@skku.edu.

\section{INTRODUCTION}

As known, owing to lots of desirable and outstanding characterizations of polymeric materials such as softness, transparency, lightness, etc., there were a large number of polymers applied in various industrial materials. Among them, polyurethane (PU) is concerned to be a contender to other synthetically polymeric materials have been attracted attention recently in various applications (1-3). For a common synthesis of $\mathrm{PU}$, it is based on a polycondensation between a segment with low molecular weight (named as pre-polymer) containing terminal hydroxyl groups and a diisocyanate (or a polyisocyanate). Besides, to reach desired PUs, it also depends on features of each reactant and polymeric material utilized in the different study purposes. For instance, Acik et al. (1) synthesized the biodegradable PU by a 
step-growth polymerization of cholic acid with various loading ratios of L-lysine diisocyanate ethyl ester that could apply in several potential applications of drug delivery and tissue engineering technologies. Concomitantly, Acik et al. (3) also conducted a synthesis of another environmentally friendly $\mathrm{PU}$ based on ring-opening polymerization of $\varepsilon$ caprolactone with the presence of cholic acid - an initiator that could utilize in particularly tissue engineering and wound dressing applications.

Herein, a "azide-alkyne" click reaction is considered a significant classification for powerful and selective reactions. Specifically, 1,2,3-triazole networks between azide and alkyne groups have been appeared to be the most reported "azide-alkyne" click reaction (4-7). It obtained some useful advantages from high reaction yields, good functional group compatibility, strong reliability, as well as in mechanical behavior improvement. Although the crosslinkers have been wildly applied in different fields, a new crosslinker with terminal alkyne group (bis-butyl succinate, BBS) has been designed and synthesized to be employed reacting with glycidyl azide polymer-based polyurethane (original PU) via the "azide-alkyne" click reaction in this study. Interestingly, the crosslinker with terminal alkyne $(-\mathrm{C} \equiv \mathrm{C}-)$ group can be synthesized by one-step method with an appropriate mole ratio of cheap reactants (Scheme 1), while glycidyl azide polyol with commercial availability is considered an azide compound containing terminal hydroxyl group is utilized in this study. Notably, this pre-polymer can bind with isocyanate $(-\mathrm{N}=\mathrm{C}=\mathrm{O})$ compound that create the original PU (Scheme 2) owing to the available hydroxyl $(-\mathrm{OH})$ groups on the pre-polymer chain. Concomitantly, the available azide $\left(-\mathrm{N}_{3}\right)$ groups on the original $\mathrm{PU}$ chain can also contribute binding with alkyne $(-\mathrm{C} \equiv \mathrm{C}-)$ compound that create modified PU (Scheme 3 ) basing on the "azide-alkyne" click reaction. In particular, the modified PU's mechanical properties with BBS are also studied to manifest the effect of mole ratio of $[\mathrm{C} \equiv \mathrm{C}] /\left[\mathrm{N}_{3}\right]$ and cross-link density in this study.

\section{MATERIALS AND METHODS}

\section{Materials}

Toluene and dichloromethane (MC, +99.0\%) were provided from Samchun Company. Magnesium sulfate $\left(\mathrm{MgSO}_{4},+99.0 \%\right)$ was purchased from Junsei Company. Succinic anhydride (SA, 99.0\%), 3-butyn1-ol (BTO, +98.0\%), 4-(dimethylamino)pyridine (DMAP, 99.0\%), and $\mathrm{N}-\mathrm{N}^{\prime}$-dicyclohexylcarbodiimide (DCC, 99.0\%) were procured from Alfa Aesar. Chloroform- $d_{1}\left(\mathrm{CDCl}_{3}\right)$ was received from Merck. Glycidyl azide polyol was supplied by a Korean Company (the possible information of glycidyl azide polyol was shortly summarized in Table 1). The utilized water was obtained from a Milli-Q ultrapure water purification system.

Table 1. Possible information of glycidyl azide polyol.

\begin{tabular}{ll}
\hline Characterization & Details \\
\hline Appearance & Amber liquid \\
Viscosity & $12 \mathrm{~Pa} \cdot \mathrm{s}$ \\
Density & $1.3 \mathrm{~g} / \mathrm{mL}$ \\
Hydroxyl equivalent weight & 2000 \\
Water content & $0.02 \%$ \\
Functionality & Between 2.5 to 3 hydroxyl groups per molecule. \\
Reactivity & Gum stocks with $1: 1-\mathrm{NCO} /-\mathrm{OH}$ typically require \\
& added catalyst at $58^{\circ} \mathrm{C}$ in a reasonable time. \\
\hline
\end{tabular}

\section{Synthesis of bis-butyl succinate (BBS)}

A mixture of SA, BTO, DMAP, DCC, and MC solvent was stirred in a two-necked round-bottomed flask at room temperature $(24 \mathrm{~h})$ and filtered through filter paper. The solution was washed with distilled water three times. The organic extracts were dried over
$\mathrm{MgSO}_{4}$ and the solvent was removed by rotary evaporator. The final crude product was purified by column chromatography (silica gel, ethyl acetate/hexane $(\mathrm{v} / \mathrm{v})=5 / 5)$. The esterification scheme of BBS synthesis is shown in Scheme 1. 


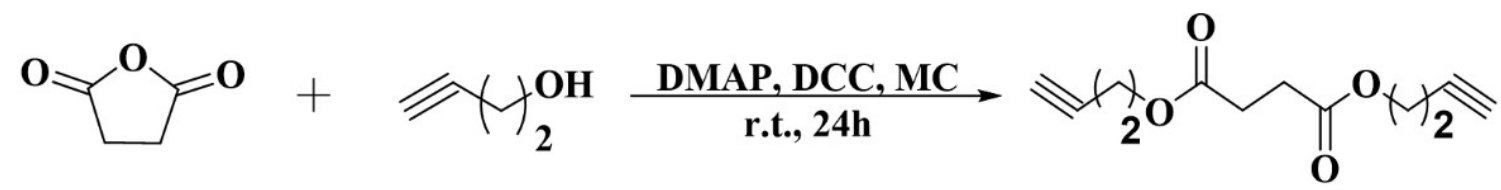

SA

BTO

BBS

Scheme 1. Esterification scheme for the synthesis of BBS.

Bis-butyl succinate (BBS): ${ }^{1} \mathrm{H}$ NMR $\left(\mathrm{CDCl}_{3}, \mathrm{ppm}\right): \delta$ $=4.07\left(\mathrm{t}, 4 \mathrm{H},-\mathrm{CH}_{2}-\mathrm{O}-\right) ; 2.53\left(\mathrm{~s}, 4 \mathrm{H},-\mathrm{CH}_{2}-\mathrm{CO}-\right)$; $2.40\left(\mathrm{dt}, 4 \mathrm{H}, \equiv \mathrm{C}-\mathrm{C}_{\boldsymbol{H}^{2}}\right) ; 1.95(\mathrm{t}, 2 \mathrm{H}, \underline{\boldsymbol{H}} \mathrm{C} \equiv \mathrm{C}-) .{ }^{13} \mathrm{C}$ $\operatorname{NMR}\left(\mathrm{CDCl}_{3}, \mathrm{ppm}\right): \delta=172.04 ; 80.12 ; 70.17 ; 62.48$; $29.01 ; 19.00$.

\section{Preparation of the Original PU}

Glycidyl azide polyol $(85.858 \mathrm{mmol})$ was dried at 60 ${ }^{\circ} \mathrm{C}$ under vacuum for $1 \mathrm{~h}$ and cooled down to 25-30

${ }^{\circ} \mathrm{C}$ for $0.5 \mathrm{~h}$. Next, IPDI $(2.160 \mathrm{mmol})$ was rapidly added into the above glycidyl azide polyol and stirred at $25-30{ }^{\circ} \mathrm{C}$. After $0.5 \mathrm{~h}, 20.0$ wt\% - TPB solution and 12.5 wt\% - DNS solution were added and continued stirring $(t=0.5 \mathrm{~h})$. Next, the above mixture was pulled into mold $(3 \mathrm{~cm} \times 8 \mathrm{~cm})$ and put in the oven at $30{ }^{\circ} \mathrm{C}$ to remove the bubble under vacuum for $3 \mathrm{~h}$; the curing process was carried out in the oven at $60^{\circ} \mathrm{C}$ for 7 days (7). The reaction scheme of the original PU without BBS is shown in Scheme 2.<smiles>CCC(O)CN</smiles>

Glycidyl azide polyol<smiles>CC1(C)CC(N=C=O)CC(C)(CN=C=O)C1</smiles>

IPDI

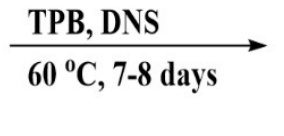

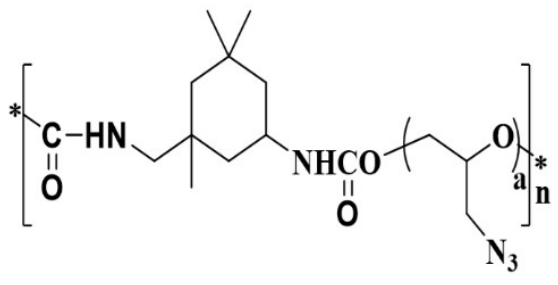

Original PU

\section{Preparation of the Modified PU}

Glycidyl azide polyol $(80.808 \mathrm{mmol})$ was dried at 60 ${ }^{\circ} \mathrm{C}$ under vacuum for $1 \mathrm{~h}$ and cooled down to 25-30 ${ }^{\circ} \mathrm{C}$ for $0.5 \mathrm{~h}$. Then, PDI $(2.270 \mathrm{mmol})$ was rapidly added into the above glycidyl azide polyol and stirred at $25-30^{\circ} \mathrm{C}$. After $0.5 \mathrm{~h}$, the synthesized BBS with various molar ratios of $[\mathrm{C} \equiv \mathrm{C}] /\left[\mathrm{N}_{3}\right], 20.0 \mathrm{wt} \%-\mathrm{TPB}$ solution, and $12.5 \mathrm{wt} \%$ - DNS solution was added and continued stirring ( $t=0.5 \mathrm{~h}$ ). Next, the mixture was pulled into mold $(3 \mathrm{~cm} \times 8 \mathrm{~cm})$ and kept in the oven at $30{ }^{\circ} \mathrm{C}$ to remove the bubble under vacuum for $3 \mathrm{~h}$; the curing process was carried out in the oven at 60 ${ }^{\circ} \mathrm{C}$ for 7 days. The reaction scheme of the original PU with BBS (modified PU) is shown in Scheme 3.

\section{Analysis Instruments}

The synthesized BBS structure was confirmed by NMR spectrometer (300 MHz, Varian Mercury Co.), which has been dissolved in $\mathrm{CDCl}_{3}$. Fourier-transform infrared spectroscopy (FT-IR) was scanned in a wavenumber range of $4000-600 \mathrm{~cm}^{-1}$ through a Nicolet 380 spectrometer. The tensile test of original and modified PUs was measured on a universal test machine (TO-100-IC, Test One) with a $20 \mathrm{~kg}$ load cell (ramp rate $=0.8 \mathrm{~mm} / \mathrm{s}$ ) at room temperature. All results for tensile tests were an average of 3 measured values. 


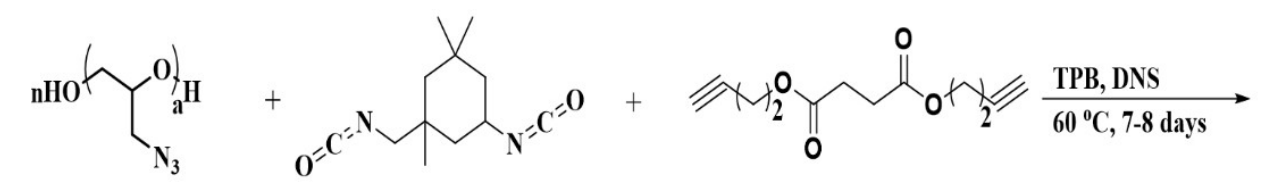

BBS

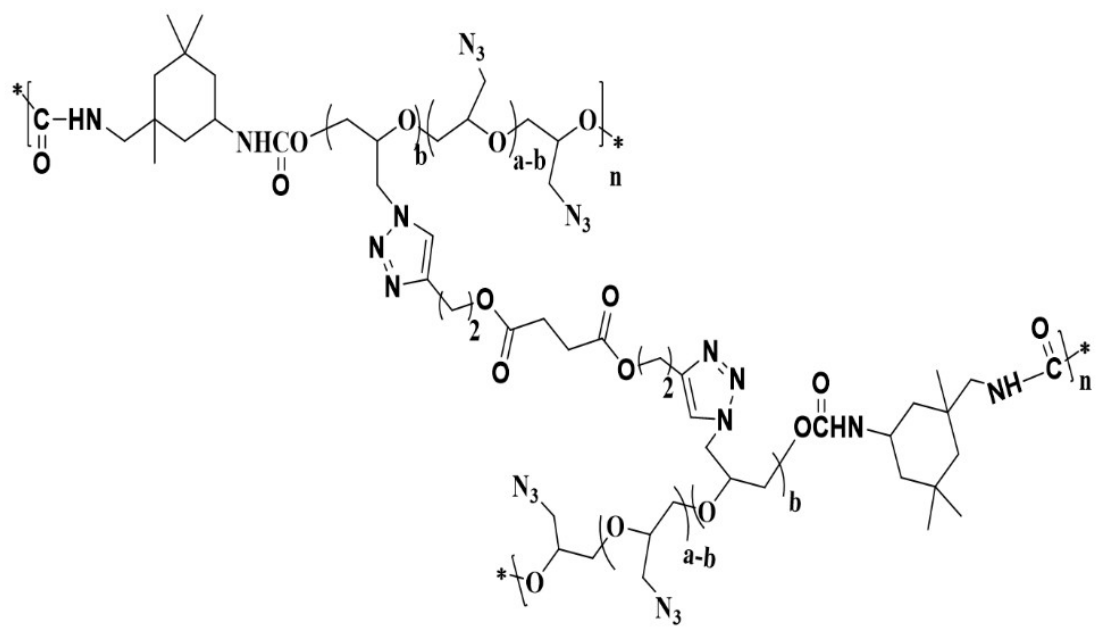

Modified PU

Scheme 3. Reaction scheme of original PU with BBS (modified PU).

\section{RESULTS AND DISCUSSION}

\section{Chemical Structure of BBS}

To determine the synthesized crosslinker's chemical structure - BBS, NMR instrument $\left({ }^{1} \mathrm{H}\right.$ and ${ }^{13} \mathrm{C}$ NMR) was employed to analyze. In the ${ }^{1} \mathrm{H}$ NMR spectrum (Figure $1 \mathrm{~A})$, a peak of the acetylenic proton $(\boldsymbol{H}-C \equiv C-)$ is regarded at $1.95 \mathrm{ppm}$; concomitantly, new peaks of two protons adjacent to oxygen (- $\left.\mathrm{CH}_{2}-\mathrm{O}-\right)$ and $\left(-\mathrm{CH}_{2}{ }^{-}\right.$ $\mathrm{CO}-$ ) are a characteristic resonance of the synthesized BBS corresponding at $4.07 \mathrm{ppm}$ and $2.53 \mathrm{ppm}$ after esterification reaction. Moreover, in the ${ }^{13} \mathrm{C}$ NMR spectrum (Figure 1B), peaks of carbons of the alkyne $(H-C \equiv \underline{\boldsymbol{C}}-)$ and $(H-\underline{\boldsymbol{C}} \equiv \mathrm{C}-)$, carboxyl oxygen $\left(-\underline{\mathbf{C}} \mathrm{H}_{2}-\mathrm{O}-\right.$ $\mathrm{CO}-)$, and adjacent carbon to alkyne $\left(\mathrm{H}-\mathrm{C} \equiv \mathrm{C}-\underline{\mathrm{C}} \mathrm{H}_{2^{-}}\right)$ are also observed at $80.12 \mathrm{ppm}, 70.17 \mathrm{ppm}, 62.48$ ppm and 19.00 ppm, respectively. Thereby, based on resultant new peaks in both the ${ }^{1} \mathrm{H}-\mathrm{NMR}$ and ${ }^{13} \mathrm{C}-\mathrm{NMR}$ spectra, it indicates that the esterification has been well used to synthesize BBS successfully - a crosslinker with terminal alkyne group through anhydride (SA) and alcohol (BTO) compounds. Furthermore, the chemical characterization of BBS was confirmed by FTIR spectra (Figure 1C) that can be focused on the new presences of carboxyl (-COO$\left.{ }^{-}\right)$ and alkyne ( $-\mathrm{C} \equiv \mathrm{C}-)$ groups on the synthesized BBS; in particular, the peaks of stretching vibration bands of alkyne groups ( $\mathrm{HC} \equiv \mathrm{C}-$, and $-\mathrm{C} \equiv \mathrm{C}-$ ) and carboxyl groups $(-C=0)$ were specifically observed at $3244 \mathrm{~cm}^{-}$ $1,2172 \mathrm{~cm}^{-1}$ and $1745 \mathrm{~cm}^{-1}$, respectively. Thereby, the acetylene groups were successfully combined on BBS molecules, as well as which was appropriate with NMR results. 
(A)

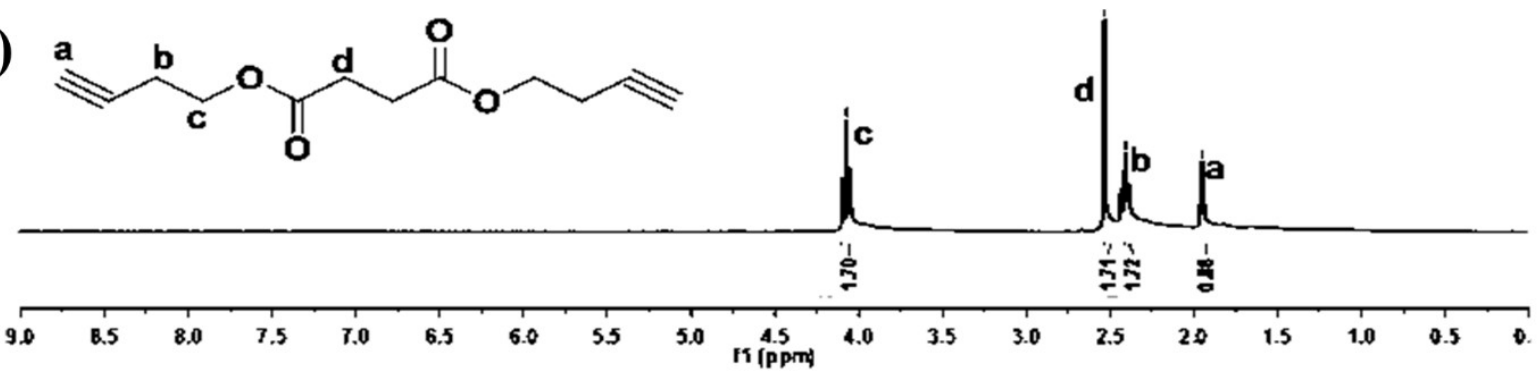

(B)

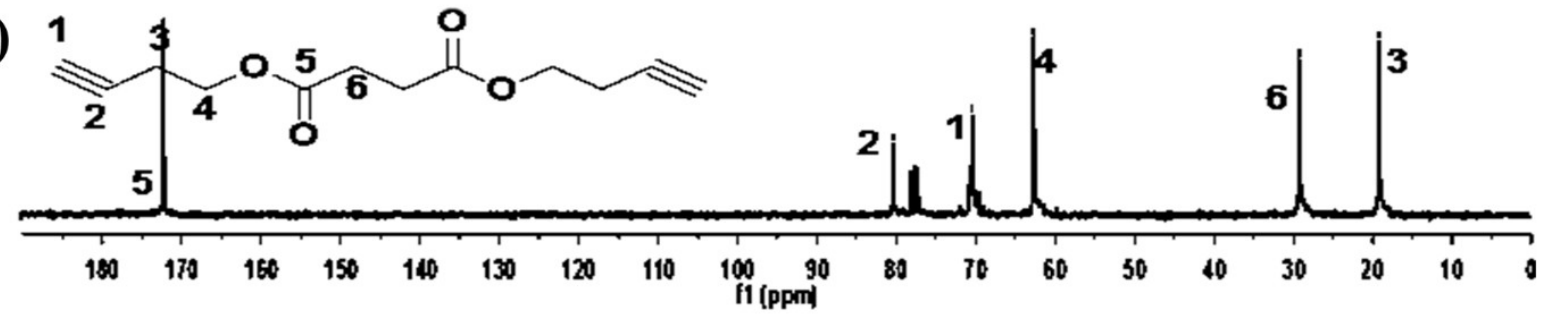

(C)

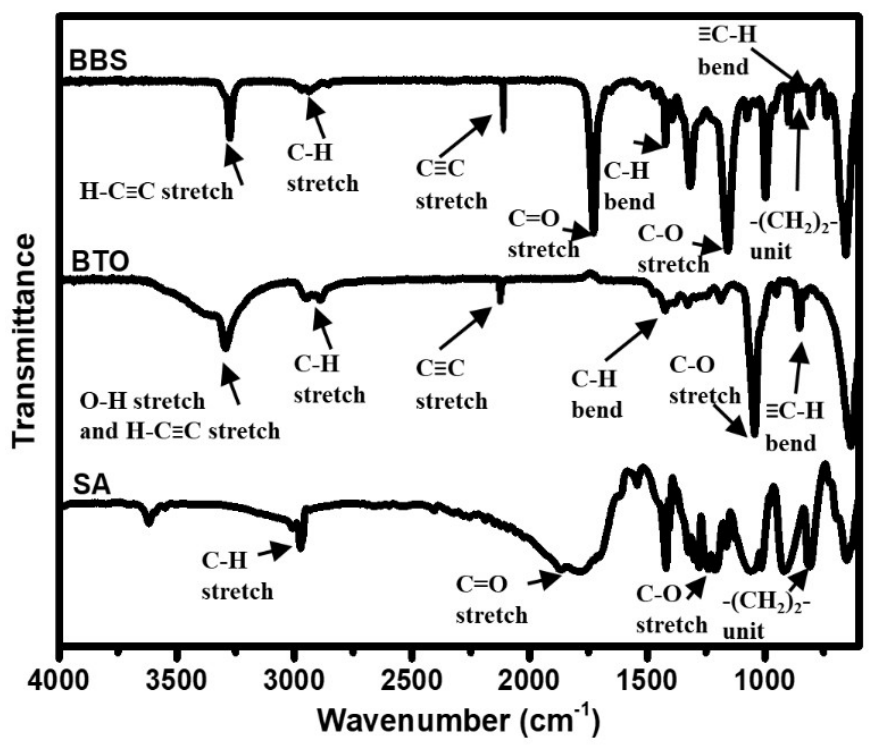

Figure 1. ${ }^{1} \mathrm{H}-\mathrm{NMR}(\mathrm{A}),{ }^{13} \mathrm{C}-\mathrm{NMR}(\mathrm{B})$ and FT-IR (C) of the synthesized BBS.

\section{Mechanical Properties of the Modified PU}

Mechanical properties of original and modified PUs were investigated through stress, strain, and Young's modulus. In stress-strain curves of the original and modified PUs (Figure 2A) were listed in Table 2, it is obvious that the modified PUs (P1 - P4) the mechanical properties were improved better than the original PU (P0). Specifically, the stress and Young's modulus of modified PUs (P1 - P4) were higher than those of the original PU (P0), whereas the strain of modified PUs (P1 - P4) is lower than that of the original PU (P0). This means that the modified PUs are harder than PO regarding the "azide-alkyne" click reaction between azide groups (original PU) and terminal alkyne group (BBS - crosslinker), as well as there is an enhancement in mechanical property of original PU cross-linked with BBS.

Moreover, compared between the modified PUs with various content of the synthesized BBS (molar ratio of $\left.[C \equiv C] /\left[N_{3}\right]=0.01-0.10\right)$, it reveals that a sudden increase in stress and Young's modulus displays harder and more ductile behaviors, which induces a transition in the intermolecular interaction of the original PU and the synthesized BBS, as well as the polymer chain stretching with external force support, which can be leading to a change in the polymer chain motion and structure variation. As a result, the 
orientation arrangement of molecular chains and stretching forces gradually increases their stress values until fracturing (8-10). As such, these suggest that the raised content of resultant 1,2,3-triazole groups basing on the "azide-alkyne" click reaction has increased the steric hindrance and lowered the torsion of the backbone chains in the modified PUs $(8,9)$, inducing an increase in their rigidity (11). Basically, these results can also support improving the desired mechanical properties of the modified PU systems by adjusting a suitable $[\mathrm{C} \equiv \mathrm{C}] /\left[\mathrm{N}_{3}\right]$ ratio (12).
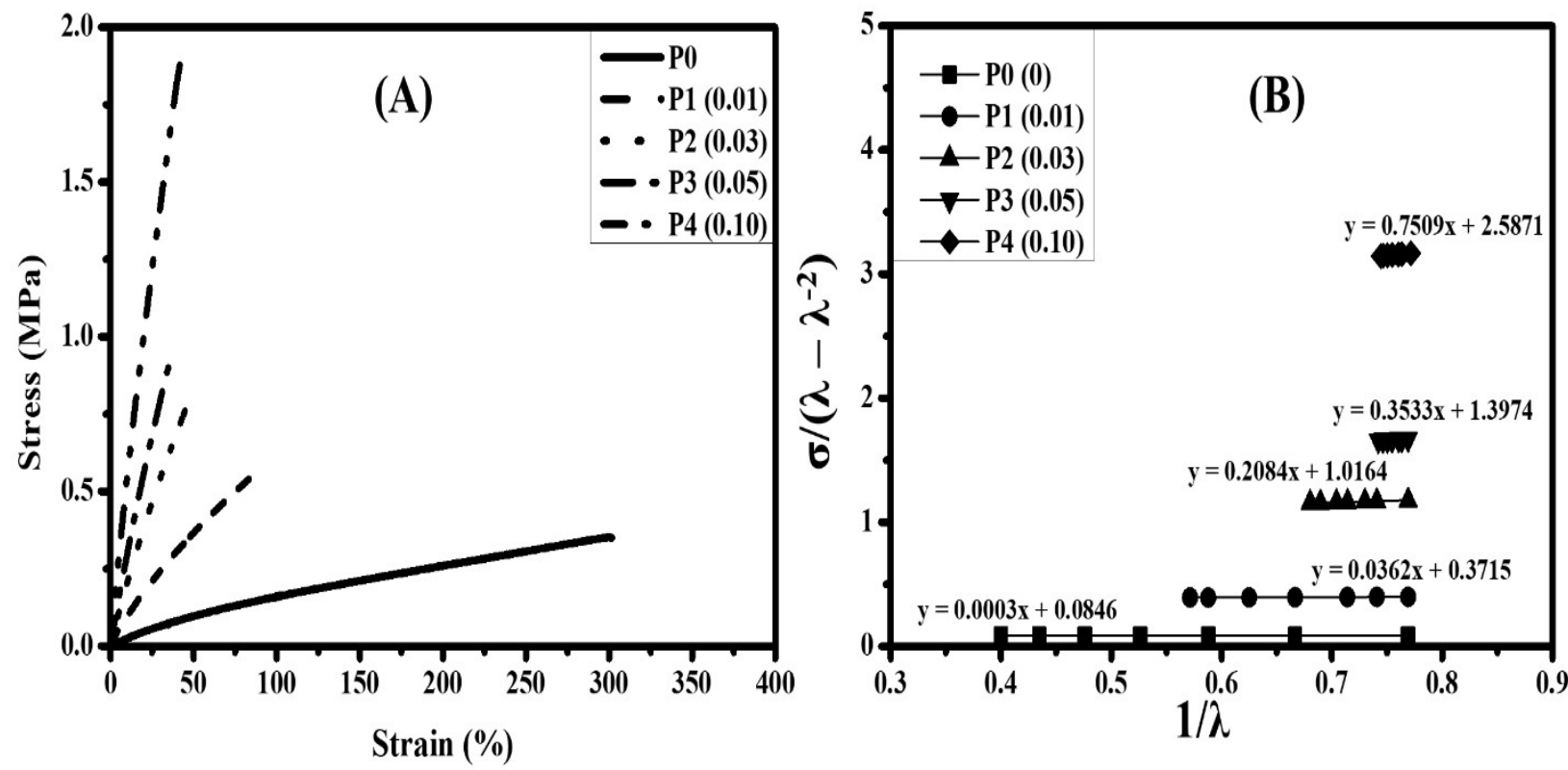

Figure 2. Stress-strain curves (A) and fitting curves for calculating cross-link density (B) of the modified PUs.

Additionally, the modified PUs with the aboveobtained mechanical properties can also be used to determine their cross-link density $\left(\mathrm{V}_{\mathrm{e}}\right)$ through the Mooney-Rivlin equation (Equation 3$)(13,14)$, as well as it contributes explaining further for a suitable relationship of cross-link density and mole ratio of $[\mathrm{C} \equiv \mathrm{C}] /\left[\mathrm{N}_{3}\right]$ in the modified PUs. Precisely, the cross- linking degree is calculated by plotting of $\sigma /\left(\lambda-\lambda^{-2}\right)$ and $1 / \lambda$ (Figure 2B). The intercept of each curve on the $\sigma /\left(\lambda-\lambda^{-2}\right)$ plot regards the $2 C_{1}$ value, whereas its slope corresponds to the $2 \mathrm{C}_{2}$ value. The below equations (Equations 1 - 3) show a relationship as follows (15):

$$
\begin{aligned}
& \mathrm{F}=2 \mathrm{~A}\left(\lambda-\lambda^{-2}\right)\left(\mathrm{C}_{1}+\mathrm{C}_{2} \lambda^{-1}\right) \\
& \frac{\sigma}{\lambda-\lambda^{-2}}=2 C_{1}+2 \frac{C_{2}}{\lambda} \\
& v_{e}=\frac{C_{1}}{R T} \quad \text { Or } \quad v_{e}=\frac{C_{1}}{\rho R T}
\end{aligned}
$$

where $\sigma$ is identified by F/A (Force/Area), $V_{e}$ is a physical cross-link density based on the stress-strain test, $\lambda$ is a strain range of $30.0-150.0 \%, R$ is a gas constant $\left(8.314 \mathrm{~J} \cdot \mathrm{mol}^{-1} \cdot \mathrm{K}^{-1}\right.$ at $\left.25{ }^{\circ} \mathrm{C}\right)$, and $\mathrm{T}$ is an absolute temperature. Herein, the $\mathrm{v}_{\mathrm{e}}$ values of original and modified PUs are summarized in Table 2, their cross-link density increase as the mole ratio of
$[\mathrm{C} \equiv \mathrm{C}] /\left[\mathrm{N}_{3}\right]$ stoichiometry be varied from 0.01 to 0.10 . This is seen as a natural consequence of the crosslinked PUs with increasing cross-link density. Overall, the relationship of cross-link density and mole ratio of $[\mathrm{C} \equiv \mathrm{C}] /\left[\mathrm{N}_{3}\right]$ in the modified PUs are genuinely suitable to the above-suggested mechanical properties. 
Table 2. Cross-link density and mechanical properties of the modified PUs.

\begin{tabular}{|c|c|c|c|c|c|c|}
\hline \multirow[b]{2}{*}{ PUs } & \multirow[b]{2}{*}{$\begin{array}{l}\text { Molar ratio of } \\
{[\mathrm{C} \equiv \mathrm{C}] /\left[\mathrm{N}_{3}\right]}\end{array}$} & \multicolumn{2}{|c|}{ Cross-link density } & \multicolumn{3}{|c|}{ Mechanical properties } \\
\hline & & $\begin{array}{c}v_{\mathrm{e}} \\
\left(\mathrm{mol} / \mathrm{cm}^{3}\right) \\
* 10^{4}\end{array}$ & $\begin{array}{c}v_{\mathrm{e}} \\
(\mathrm{mol} / \mathrm{g}) \\
* 10^{4}\end{array}$ & $\begin{array}{l}\text { Stress } \\
\text { (MPa) }\end{array}$ & $\begin{array}{c}\text { Strain } \\
(\%)\end{array}$ & $\begin{array}{c}\text { Young's } \\
\text { modulus } \\
(\mathrm{MPa})\end{array}$ \\
\hline PO & 0 & 0.175 & 0.131 & $0.361 \pm 0.016$ & $320.8 \pm 26.9$ & $0.254 \pm 0.013$ \\
\hline P1 & 0.01 & 0.750 & 0.561 & $0.546 \pm 0.003$ & $88.4 \pm 2.4$ & $0.865 \pm 0.017$ \\
\hline P2 & 0.03 & 2.051 & 1.508 & $0.756 \pm 0.057$ & $45.1 \pm 3.7$ & $2.024 \pm 0.010$ \\
\hline P3 & 0.05 & 2.820 & 2.057 & $0.914 \pm 0.007$ & $35.8 \pm 0.6$ & $2.997 \pm 0.015$ \\
\hline P4 & 0.10 & 5.221 & 3.842 & $1.681 \pm 0.198$ & $36.6 \pm 5.2$ & $5.453 \pm 0.197$ \\
\hline
\end{tabular}

\section{CONCLUSION}

In summary, BBS - a new crosslinker with terminal alkyne group, has been synthesized successfully from the esterification of anhydride (SA) and alcohol (BTO) compounds incorporated with original $\mathrm{PU}$ well as the formation of 1,2,3-triazole groups. Besides, the original PU cross-linked with the above-synthesized BBS has achieved a significant improvement in their mechanical properties. Significantly, the stress and Young's modulus of the modified PUs increase, whereas their strain decreases on increasing the content of the synthesized BBS to the original PU matrix involving the increased rigid triazole networks. Moreover, the cross-link densities of the modified PUs increase with the BBS content through the MooneyRivlin equation, as well as there is an enhancement in the mechanical property of the original PU crosslinked with BBS. Thereby, the different mole ratio of $[\mathrm{C} \equiv \mathrm{C}] /\left[\mathrm{N}_{3}\right]$ prepared in the present study can reveal new approaches for the design and future application of the original PU with alkyne compounds, as well as their desired cross-link densities can be controlled easily for powerful and selective reactions.

\section{ACKNOWLEDGMENTS}

The authors thank the support of Can Tho University.

\section{REFERENCES}

1. Acik G, Karabulut HRF, Altinkok C, Karatavuk AO. Synthesis and characterization of biodegradable polyurethanes made from cholic acid and L-lysine diisocyanate ethyl ester. Polymer Degradation and Stability. 2019; 165: 43-8.

2. Caraculacu AA, Coseri S. Isocyanates in polyaddition processes. Structure and reaction mechanisms. Prog Polym Sci. 2001; 26: 799-851.
3. Acik B, Acik G, Erdemi H. Synthesis and characterization of bile acid, poly ( $\varepsilon$-caprolactone) and L-lysine diisocyanate ethyl ester based polyurethanes and investigation of their biodegradability properties. Eur Polym J. 2021; 146: 110247.

4. Binder WH, Sachsenhofer R. 'Click' chemistry in polymer and material science: An update. Macromol Rapid Comm. 2008; 29: 952-81.

5. Diaz DD, Punna S, Holzer P, Mcpherson AK, Sharpless KB, Fokin VV, Finn MG. Click chemistry in materials synthesis. 1. Adhesive polymers from copper-catalyzed azide-alkyne cycloaddition. J Polym Sci Pol Chem. 2004; 42: 4392-403.

6. Rostovtsev VV, Green LG, Fokin VV, Sharpless KB. A stepwise Huisgen cycloaddition process: Copper(I)catalyzed regioselective "ligation" of azides and terminal alkynes. Angew Chem Int Ed. 2002; 41: 2596-9.

7. Vo TS, Vo TTBC. Preparation and Characterization of Bis-Propargyl-Succinate, and its Application in Preliminary Healing Ability of Crosslinked Polyurethane using" Azide-Alkyne" Click. Journal of Engineering Science \& Technology Review. 2020; 13.

8. Wool RP. Mechanisms of frequency shifting in the infrared spectrum of stressed polymer. Journal of Polymer Science, Polymer Physics Edition. 1975; 13: 1795-808.

9. Wool RP. Infrared studies of deformation in semicrystalline polymers. Polymer Engineering and Science. 1980; 20: 805-15.

10. Cifre JGH, de la Torre JG. Orientation of polymer chains in dilute solution under shear: Effect of chain 
model and excluded volume. Macromol Theor Simul. 2004; 13: 273-9.

11. Ward IM, Hadley DW. An introduction to the mechanical properties of solid polymers. John Wiley \& Sons, Chichester,. 2004; ISBN: 0-471-93887-4.

12. Keicher T, Kuglstatter W, Eisele S, Wetzel T, Krause $\mathrm{H}$. Isocyanate-Free Curing of Glycidyl Azide Polymer (GAP) with Bis-Propargyl-Succinate (II). Propellants, Explosives, Pyrotechnics. 2009; 34: 2107.
13. Flory PJ. Statistical mechanics of swelling of network structures. J Chem Phys. 1950; 18: 108 11.

14. Mullins L. Determination of degree of crosslinking in natural rubber vulcanizates (Part 3). Journal of Applied Polymer Science. 1959; 1: 1 - 7.

15. Hagen R, Salmen L, Stenberg B. Effects of the type of crosslink on viscoelastic properties of natural rubber. J Polym Sci Polym Phys. 1996; 34: 19972006. 